\title{
ESTUDO MORFOLÓGICO NO MÚSCULO GASTROCNÊMIO DE CAMUNDONGOS C57 BL10 SUBMETIDOS À INGESTÃO PROLONGADA DE ETANOL
}

\author{
JOÃO BATISTA GUEDES E SILVA*, JORGE A. DA COSTA LISBOA**, \\ MARCOS R. G. FREITAS ${ }^{\star \star *}$, OSVALDO J. M. NASCIMENTO***
}

RESUMO - Os efeitos do alcoolismo crônico no músculo gastrocnêmio de camundongos bem nutridos foram estudados morfologicamente com a finalidade de se avaliar a hipótese de que o etanol exerce um papel tóxico direto sobre o músculo esquelético. Foram usados 30 camundongos C57BL10 machos, adultos jovens, divididos em dois grupos: Grupo A (controle) consistindo de 10 camundongos que beberam água e Grupo B (alcoólico) de 20 camundongos que beberam etanol a $25 \%$. Todos os animais receberam uma ração balanceada de laboratório e foram mantidos nesse regime ad libitum nas mesmas condiçóes ambientais durante 48 semanas e pesados uma vez por semana. $O$ consumo diário de dieta e a ingestão calórica foram calculados tendo os animais apresentado substancial ganho de peso, não mostrando qualquer sinal de desnutrição. Ao final do experimento os animais foram sacrificados para estudos morfológicos. Pela microscopia óptica não foram encontradas alteraçőes. Importantes anormalidades foram observadas pela microscopia eletrônica em todos os espécimens.O retículo sarcoplasmático mostrou-se frequentemente dilatado, resultando na formação de grandes vesiculas e envolvendo as cisternas terminais com deslocamento das triades. Áreas de estreitamento, ruptura e perda de miofibrilas ocorreram assim como zonas de completa desorganização de miofibrilas com perda do padrão estriado normal. As mitocondrias estavam em linhas gerais dentro dos limites da normalidade. Agregados tubulares peculiares vistos comumente na paralisia periódica e outras condições patológicas humanas, foram encontrados tanto no músculo dos camundongos controles como no dos alcoólicos. Os nervos intramusculares assim como as junçðes neuromusculares mostravam-se normais. Importantes anormalidades nos capilares musculares foram observadas, consistindo de tumefação das células endoteliais e de espessamento da lâmina basal. Difusa infiltração lipídica microvesicular foi vista no citoplasma dos hepatócitos parecendo constituir uma evidência a mais da ação tóxica do etanol sobre o organismo. Concluimos que a ingestão prolongada de etanol, representando $14,4 \%$ de calorias totais, produz no músculo gastrocnêmio de camundongos C57BL10 bem nutridos um elenco de alteraçðes ultraestruturais que refletem um efeito tóxico direto sobre o músculo esquelético. As alterações constatadas são semelhantes àquelas descritas na miopatia alcoólica crônica humana

PALAVRAS-CHAVE: ingestão prolongada de etanol, camundongos C57BL10, músculo gastrocnêmio, alteraçðes uitraestruturais.

Study of ultrastructural alterations in gastrocnemius muscle of C57 BL10 mice after prolonged ethanol ingestion

ABSTRACT - The effects of chronic alcoholism on gastrocnemius muscle of well-nourished mice were morphologically studied to test the direct toxic role of ethanol on skeletal muscle. Thirty male young adult C57BL 10 mice were divided in two groups: Group A (control) consisting of ten mice that drank water and Group B (alcoholic) consisting of twenty mice that drank $25 \%$ ethanol. All mice were allowed a balanced laboratory chow. The animals were kept on this ad libitum regimen under the same conditions of environment for 48 weeks and were weighed once a week. The daily dietary consumption and caloric intake were estimated, the animals having had a substantial weight gain, showing no signs of malnutrition. At the end of the experiment the animals were killed for morphological studies. No abnormalities were observed by conventional microscopy.

Dr. J.B. Guedes e Silva - Rua Miguel Pereira Sarmento 240 - 24310-420 Niterói RJ - Brasil

Estudo do Departamento de Patologia da Faculdade de Medicina da Universidade Federal Fluminense (UFF): *Professor Títular de Anatomia Patológica do Departamento de Patologia; **Professor Adjunto do Departamento de Patologia; ***Professor Titular da Disciplina de Neurologia. Aceite: 17-janeiro-1996. 
Striking deviations from normal were verified by electron microscopy in all specimens. Dilatation of sarcoplasmic reticulum was a common feature, sometimes resulting in the formation of large vesicles and involving the terminal cisternae with the displacement of the triads. Areas of narrowing, splitting and loss of myofibrils were seen. Zones of complete disorganization of miofibrils could be occasionally observed. Mitochondria were generally normal. Peculiar tubular aggregates seen commonly in periodic paralysis and other human pathological conditions, were encountered in both control and alcoholic mice. Intramuscular nerves and neuromuscular junctions were normal. Important abnormalities in muscle capillaries were observed, consisting of swelling of endothelial cells and thickening of the basal lamina. A diffuse microvesicular lipid infiltration was seen in the cytoplasm of the hepatocytes which seems to be a further evidence of the toxic role played by ethanol. We concluded that prolonged ingestion of ethanol, representing $14.4 \%$ of total calories, produces in the gastrocnemius muscle of well-nourished C57BL10 mice a distinct spectrum of ultrastructural changes which reflects a direct toxic effect on the skeletal muscle. These alterations are similar to those described in human chronic alcoholic myopathy.

KEY WORDS: prolonged ethanol ingestion, C53BL10 mice, gastrocnemius muscle, ultrastructural changes.

As complicaç̃es que o alcoolismo crônico acarreta para diferentes órgãos e sistemas constituem hoje um capítulo amplamente reconhecido pela ciência médica. Na patologia do alcoolismo destacamse anormalidades hepáticas, gastrointestinais, cardiacas, neurológicas, musculares, hematopoiéticas e metabólicas. O mecanismo de ação direta do tóxico e/ou seus metabólitos sobre o organismo é atualmente aceito por expressivo número de pesquisadores. Ekbom e col. ${ }^{9}$ foram os primeiros a chamar a atenção para uma sindrome muscular crônica caracterizada por fraqueza e atrofia proximais que surgia como complicação do uso prolongado de etanol. A partir de então foram inúmeras as contribuiçðes ao estudo da miopatia alcoólica crônica, devendo ser citados os de Perkoff e col. ${ }^{28.29}$ Martin e col..$^{22}$ Rubin e col. ${ }^{34}$ e Langohr e col ${ }^{19}$. Um significativo quadro histológico é visto no estádio crônico da miopatia alcoólica humana. Uma grande variação no diâmetro das fibras foi observada, alguns fasciculos sendo reduzidos apenas a fibras atrofiadas. Foram também verificados aumento no número dos núcleos subsarcolemais, aumento do conjuntivo intersticial e substituição de fibras destruídas por tecido adiposo $0^{9.16}$. Nas formas subclínicas da doença o exame histológico mostra alteraçôes muito modestas como aumento dos núcleos subsarcolemais e ocasional atrofia de fibras musculares ${ }^{30}$. Estudos histoquímicos têm demonstrado ser a atrofia do tipo 2 o achado mais importante na miopatia alcoólica crônica. Rossouw e col. ${ }^{33}$, Langohr e col. ${ }^{19}$ e Ferraz e col. ${ }^{11}$ descreveram, além da atrofia do tipo 2, a presença de fibras angulares e agrupamentos de fibras do mesmo tipo histoquímico ("fibre type grouping"). Em estudo experimental, Trounce e col. ${ }^{3 *}$, trabalhando com ratos Sprague-Dawley, associaram a atrofia de fibras do tipo 2 a significante depleção de várias enzimas glicolíticas.

São escassos na literatura do alcoolismo crônico estudos experimentais sobre as alterações musculares. Song e Rubin ${ }^{37}$ e Rubin e col..$^{34}$ encontraram importantes alteraçס̃es ultraestruturais em três voluntários não alcoólicos que se submeteram à ingestão crônica de etanol durante 28 dias. $\mathrm{O}$ estudo das biópsias musculares ao microscópio óptico não revelou qualquer alteração. Não houve quadro clínico de miopatia embora a atividade da creatinofosfoquinase estivesse aumentada. A microscopia eletrônica revelou pronunciado edema intracelular, espaços intermiofibrilares alargados contendo glicogênio e goticulas lipidicas, dilatação do retículo sarcoplasmático e mitocôndrias irregulares, muitas delas aumentadas de tamanho. Baruah e col.', em estudo experimental em que administraram etanol a ratos Sprague-Dawley durante seis semanas, observaram dilatação do retículo sarcoplasmático e de túbulos transversos, formação de megamitocôndrias, ruptura de cristas mitocondriais e densas inclusões na matriz mitocondrial. Constataram ainda dissolução de bandas $Z$ e lise de miofibrilas.

O objetivo do presente estudo experimental é analisar as alterações morfológicas, ao microscópio óptico e eletrônico, verificadas no músculo esquelético de camundongos C57BL10 submetidos a longo período de administração alcoólica. O camundongo C57BL 10 foi selecionado como modelo experimental especialmente pela sua preferência geneticamente determinada para beber uma solução a $10 \%$ de etanol 
em lugar de água ${ }^{32}$, assegurando-se dessa forma uma adequada ingestão ad libitum de solução moderadamente concentrada de etanol. Considerando-se que a deficiência nutricional é condição frequentemente associada ao alcoolismo crônico, levando a frequentes controvérsias de natureza patogenética, foi nosso propósito que a ingestão prolongada de solução alcó́lica que representasse moderado consumo calórico, fosse capaz de produzir alteraçoes morfológicas no músculo esquelético sem prejuizo da ingestão de quantidades adequadas de nutrientes, dessa forma possibilitando-nos demonstrar que o etanol exerce sobre esse tecido uma ação tóxica direta independente de fatores de ordem nutricional. Sendo o figado o principal órgão de metabolismo do etanol e frequentemente lesado no alcoolismo crônico, tomou-se relevante o exame ao microscopio óptico do tecido hepático dos animais alcoólicos e controles como um parâmetro a mais do efeito desse tóxico no organismo.

\section{MATERIAL E MÉTODOS}

Foram utilizados 30 camundongos de linhagem C57BL10, machos, de dois meses de idade, pesando em média 22,47 gramas, obtidos no biotério do Instituto de Biologia da UFF. Os animais foram selecionados pelos seus pesos e distribuidos em dois grupos pertencentes ao mesmo universo através de suas médias: Grupo A (controle) - 10 camundongos; Grupo B (alcoólico) - 20 camundongos. Foram a seguir alojados em três gaiolas, contendo cada gaiola 10 camundongos, sendo para isso o Grupo B (alcoólico) dividido em dois sub-grupos de 10 camundongos. As gaiolas eram de fundo plástico com tampa em grade metálica e comedouro em depressão apropriada para 0 alimento sólido. Quanto a dieta líquida, era fornecida em bebedouros plásticos graduados até $250 \mathrm{ml}$ adaptados à gaiola. Os animais, durante todo o periodo experimental, foram mantidos em temperatura ambiente no biotério do Laboratório de Patologia Experimental do Departamento de Patologia da UFF. Foram todos alimentados com dieta sólida comercial de laboratório cuja composição por 100 gramas, fornecida pelo Moinho São Cristóvão, era a seguinte: protéina bruta $17,8 \mathrm{~g} \%$; gordura $4,3 \mathrm{~g} \%$; carboidrato $61,2 \mathrm{~g} \%$; sais minerais e fibra $16,7 \mathrm{~g} \%$. Quanto à dieta líquida, o Grupo A (controle) recebeu água e o Grupo B (alcoólico) uma solução de álcool etilico a $25 \%$ volume/volume em água, ambas levemente adocicadas com Sucaryl-Abbott (cinco gotas de Sucaryl em $1000 \mathrm{~mL}$. Cada 20 gotas de Sucaryl contêm: ciclamato de cálcio $-0,16 \mathrm{~g}$; sacarina sódica $-0,10 \mathrm{~g}$ ). Os animais receberam alimentação sólida e liquida ad libitum. Foram pesados uma vez por semana, sendo também medido e anotado semanalmente o consumo de dieta sólida e líquida. Após 48 semanas de experimentaçăo os animais foram sacrificados sob anestesia superficial pelo éter. Foram retirados fragmentos do músculo gastrocnêmio para estudo ao microscópio eletrônico e do músculo gastrocnêmio e do lobo esquerdo do figado para exame ao microscópio óptico.

Microscopia óptica. Fragmentos do músculo gastrocnêmio foram fixados por imersão em solução de

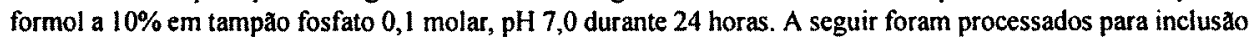
em parafina, tendo sido feitos cortes de aproximadamente seis micrômetros de cada fragmento. As secç̃es histológicas foram coradas pela hematoxilina-eosina, pela hematoxilina fosfotúngstica de Mallory e pelo tricrômico de Gomori. Fragmentos do figado de cada animal foram igualmente processados para a microscopia óptica, coradas as seç̧ôes histológicas pela hematoxilina-eosina.

Microscopia eletrônica. Imediatamente após o sacrificio foram retirados fragmentos do músculo gastrocnêmio e imersos em aldeído glutárico a $2,5 \% \mathrm{em}$ tampão cacodilato de sódio 0,1 molar, pH 7,4 a $4 \mathrm{C}^{\circ}$. A seguir foram clivados em pequenos fragmentos de aproximadamente $1 \mathrm{~mm} 3$ que foram fixados em aldeido glutárico por 2 horas a $4 \mathrm{C}^{\circ}$, lavados em tampão cacodilato de sódio e pós-fixados em tetróxido de ósmio a $1 \%$ em tampão cacodilato de sódio 0,1 molar, $\mathrm{pH} 7,4$ durante 1 hora a $4 \mathrm{C}^{\circ}$. Os fragmentos foram desidratados e incluídos em resina poliéster Polylite 8001 , segundo Coiro e Brunner $\mathrm{Jr}^{5}$. Cortes semifinos de I micròmetro e cortes ultrafinos foram obtidos no ultramicrótomo Sorvall $\mathrm{Mt} 6000$. Os cortes semifinos foram corados pelo Azure $1{ }^{15}$ e pelo azul de toluidina e examinados ao microscópio óptico para escolha dos fragmentos.Cortes semifinos obtidos do tecido hepático, corados pelo azul de toluidina, foram analisados ao microscópio óptico para avaliaçđo da quantidade de gordura depositada nas células hepáticas. Os cortes ultrafinos, obtidos de no minimo três blocos, foram montados em grades de cobre de 300 quadrículas e contrastados com acetato de uranila em metanol e com citrato de chumbo. As preparaçðes foram examinadas ao microscópio eletrônico EM 109 da Carl-Zeiss e eletronmicrografadas com filme de 35mm Kodatith Orthofilm 6556 type 3 da Kodak.

Análise estatistica. Os resultados foram expressos como média \pm desvio padrăo. Para analisar a significância da diferença entre dois valores foi utilizado o teste $t$ de Student.

\section{RESULTADOS}

No decorrer do experimento morreram dois animais do Grupo A (controle) e três animais do Grupo B (alcoólico), que não foram substituídos. Nenhum dos animais de qualquer gaiola mostrou distúrbios de apreensão, 
motricidade ou no sentido de direção. Foram calculadas as ingestơes médias semanais e, a partir destas, as ingestðes diárias de dieta sólida (valores expressos em gramas e calorias) e de dieta liquida (valores expressos em mililitros e calorias) durante o periodo experimental de 48 semanas. Foram calculadas ainda as ingestðes médias diárias de proteína, gordura e carboidrato para o Grupo A (controle) e de proteina, gordura, carboidrato e álcool para o Grupo B (alcoólico). Os dados expressos em calorias foram calculados a partir dos pesos da dieta sólida ingerida, usando-se os seguintes valores: 1 grama de proteina fornece 4 calorias, 1 grama de gordura 9 calorias e 1 grama de carboidrato 4 calorias. O valor calculado para 1 grama de dieta sólida foi 3,55 calorias. $O$ valor calórico calculado para 1 mililitro de dieta líquida, representada pela solução de álcool a $25 \%$, foi 1,42 calorias, de acordo com Porta e Gomez-Dumm ${ }^{31}$. O consumo médio diário de dieta sólida, calculado a partir dos dados semanais, foi 6,07 g/camundongo/dia para os camundongos do Grupo $\mathrm{A}$ (controle) e de $4,70 \mathrm{~g} / \mathrm{camundongo} /$ dia para os camundongos do Grupo B (alcólico). O consumo médio diário de dieta liquida foi $1,96 \mathrm{~mL} /$ camundongo/dia para os camundongos do Grupo B (alcoólico).Consequentemente os animais do Grupo A (controle) ingeriram sob a forma de dieta sólida 21,5 calorias/camundongo/dia, sendo $20,0 \%$ provenientes de proteina, 10,7\% de gordura e $69,3 \%$ de carboidrato.Os animais do Grupo B (alcoólico) ingeriram 16,7 calorias/ camundongo/dia provenientes de dieta sólida e 2,8 calorias/camundongo/dia provenientes da ingeståo líquida, totalizando 19,5 calorias/camundongo/dia, sendo $17,4 \%$ provenientes de proteina, $9,2 \%$ de gordura, $59,0 \%$ de carboidrato e $14,4 \%$ de álcool (Tabela).

Evolução ponderal. Os animais de ambos os grupos apresentaram-se em bom estado geral durante todo o periodo experimental, sem qualquer sinal de deficiência nutricional, desenvolvendo-se bem, nåo havendo diferença significativa entre os grupos em todos os tempos considerados (Fig 1).

Exame morfológico. Foram escolhidos aleatoriamente 5 animais do Grupo A (controle) e 10 animais do Grupo B (alcoólico) para exame do músculo gastrocnêmio ao microscópio óptico e eletrônico.

Microscopia óptica. A estrutura muscular dos animais do Grupo B (alcoólico) pareceu identica a dos animais do Grupo A (controle), sem alteraçðes patológicas ao exame ao microscópio óptico. Cortes semifinos de músculo dos animais do Grupo A (controle) e do Grupo B (alcoólico) mostraram nas fibras musculares estruturas alongadas, ovalares ou elipticas, de tonalidade azul-escuro, localizadas no centro da fibra ou abaixo do sarcolema, compativeis com agregados tubulares (Fig 2a e 2b). As preparaçðes histológicas do figado dos 5 animais do Grupo A (controle) coradas pela hematoxilina-eosina mostraram aspecto habitual. As preparaçסes do figado de 10 animais do Grupo B (alcoólico) mostraram fina vacuolizaçào nos hepatócitos (Fig 2c)

Tabela. Ingestão média diária de dieta sólida (DS) e de dieta liquida (DL) por camundongo durante 48 semanas estimada a partir da ingestão semanal.

\begin{tabular}{|c|c|c|c|c|c|}
\hline \multirow[b]{2}{*}{ Grupo } & \multicolumn{4}{|c|}{ DS } & \multirow{2}{*}{$\frac{\mathrm{DL}}{\text { Álcool }}$} \\
\hline & Proteina & Gordura & Carbroidrato & Total & \\
\hline \multirow[t]{5}{*}{ A } & & & & $2.57(\min )$. & \\
\hline & (a) 1,08 & 0,26 & 3,71 & ${ }^{*} 6,07$ & - \\
\hline & & & & 8,14 (máx.) & \\
\hline & (b) 4,3 & 2,3 & 14,9 & 21,5 & - \\
\hline & (c) 20,0 & 10,7 & 69,3 & 100,0 & - \\
\hline \multirow[t]{5}{*}{ B } & & & & $2,50(\mathrm{~min})$. & $1,01(\mathrm{~min})$. \\
\hline & (a) 0,84 & 0,20 & 2,88 & $* 4,70$ & (d) 1,96 \\
\hline & & & & $7,18(\max )$. & 2,51 (máx.) \\
\hline & (b) 3,4 & 1,8 & 11,5 & 16,7 & 2,8 \\
\hline & (c) 17,4 & 9,2 & 59,0 & 85,6 & 14,4 \\
\hline
\end{tabular}

Os valores são expressos em g/camundongo/dia (a), cal/camundongo/dia (b) percentagem (c) e mL/ camundongo/dia (d). Grupo A (controle): 8 a 10 animais. Grupo B (alcoólico): 17 a 20 animais; (mín.) e (máx.) correspondem à ingestào minima e máxima.

*incluindo residuos (outros componentes: sais minerais e fibra). 


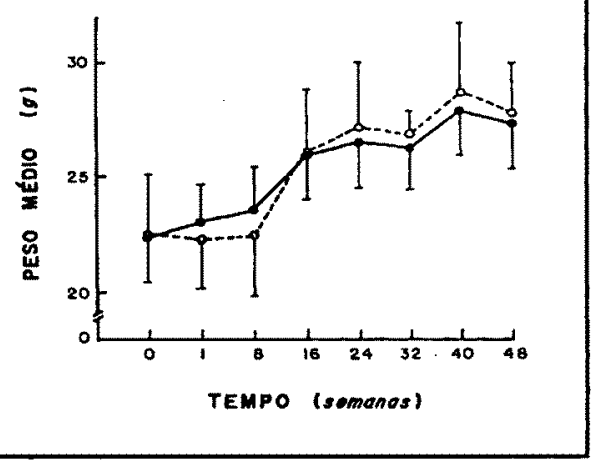

Fig l. Evolução pondera; Abcissas: durą̧ão do experimento expressa em semanas. Ordenadas: peso médio dos camundongos expresso em gramas (g). (o--.-o): Grupo controle: $(\leftrightarrow)$ ): Grupo alcoólico. Os pontos correspondem ao peso médio \pm desvio padrão (barras verticais) de 8-10 animais (grupo controle) e de 17-20 animais (grupo alcoólico).

do reticulo sarcoplasmático, por vezes sob a forma vesicular, podendo estender-se inclusive às cisternas terminais alterando a configuração das tríades (Fig 3 a e 3b). Tal alteração envolvia extensos segmentos de fibras que se alternavam com outras fibras de padräo normal. Areas de adelgaçamento de miofibrilas com alargamento dos espaços intermiofibrilares, assim como zonas de ruptura ou mesmo de franca lise ou dissolução de miofibrilas foram frequentemente constatadas. Os espaços deixados pelas miofibrilas adelgaçadas e por sua dissolução, eram ocupados por mitocôndrias de forma e tamanho variados, grânulos de glicogênio e corpos densos lisossomais (Fig 4a, 4b e 4c). Mais raramente foram constatadas fibras com segmentos de total desorganização da arquitetura miofibrilar que era substituida por uma massa de miofilamentos dispostos ao acaso em meio d̀ qual remanescentes de organelas eram observados. De maneira geral as mitocôndrias estavam dentro dos padrǒes da normalidade, quer quanto ao número, quer quanto ao tamanho ou forma. Agregados tubulares, idênticos aos observados nos animais controles, foram encontrados em fibras com caracteristicas das do tipo 2 , em maior ou menor número, $\mathrm{em}$ todos os animais alcoólicos. Por vezes múltiplos em uma mesma fibra, os agregados eram vistos no centro da fibra ou, mais raramente, sob o sarcolema (Fig 5a). Os nervos intramusculares mostravam axônios mielinicos e amielínicos de padrăo condizente com a normalidade, apresentando o endoneuro colágeno em quantidade habitual. Da mesma forma não foram observadas quaisquer anormalidades nas junçðes neuromusculares. Importantes alteraçð̃es foram observadas nos capilares intramusculares. $O$ conceito de capilar por nós usado foi 0 de Lin e col. ${ }^{20}$, restringindo-se a vasos que consistiam exclusivamente de endotélio, lâmina basal e uma camada incompleta de pericito e cujo diâmetro interno, medido a partir da borda interna da lâmina basal, não tinha mais do que 20 micrômetros. Uma alteração constante foi a tumefação por edema das células endoteliais. Importante a se assinalar foi o achado de grau variável de espessamento da lâmina basal que frequentemente se apresentava densa e por vezes bastante irregular. Graus extremos de espessamento da lâmina basal podiam refletir-se na morfologia do vaso como um todo, observando-se nestes casos imagens retraidas e distorcidas de capilares, por vezes com redução de sua luz (Figs $5 b, 5 c$ ).

\section{DISCUSSÃO}

Durante o período de um ano, o Grupo B (alcoólico) de camundongos ingeriu uma solução a $25 \%$ de etanol ad libitum e uma dieta sólida comercial de laboratório, não tendo apresentado ao final do experimento qualquer sinal de desnutrição quando comparado com o Grupo $\mathrm{A}$ (controle). $\mathrm{A}$ ração continha em sua composição percentuais de proteína, gordura e carboidrato condizentes com os de dietas que parecem adequadas para camundongos ${ }^{25}$. Segundo o "Manual para técnicos em animais de laboratório" da Organização Panamericana da Saúde ${ }^{27}$, o consumo médio diário por camundongo de uma dieta balanceada é de 4 a $6 \mathrm{~g}$. Canolty e Koong ${ }^{3}$ mostraram que camundongos selecionados ao acaso para um crescimento regular de 21 aos 42 dias, alimentados ad libitum, 


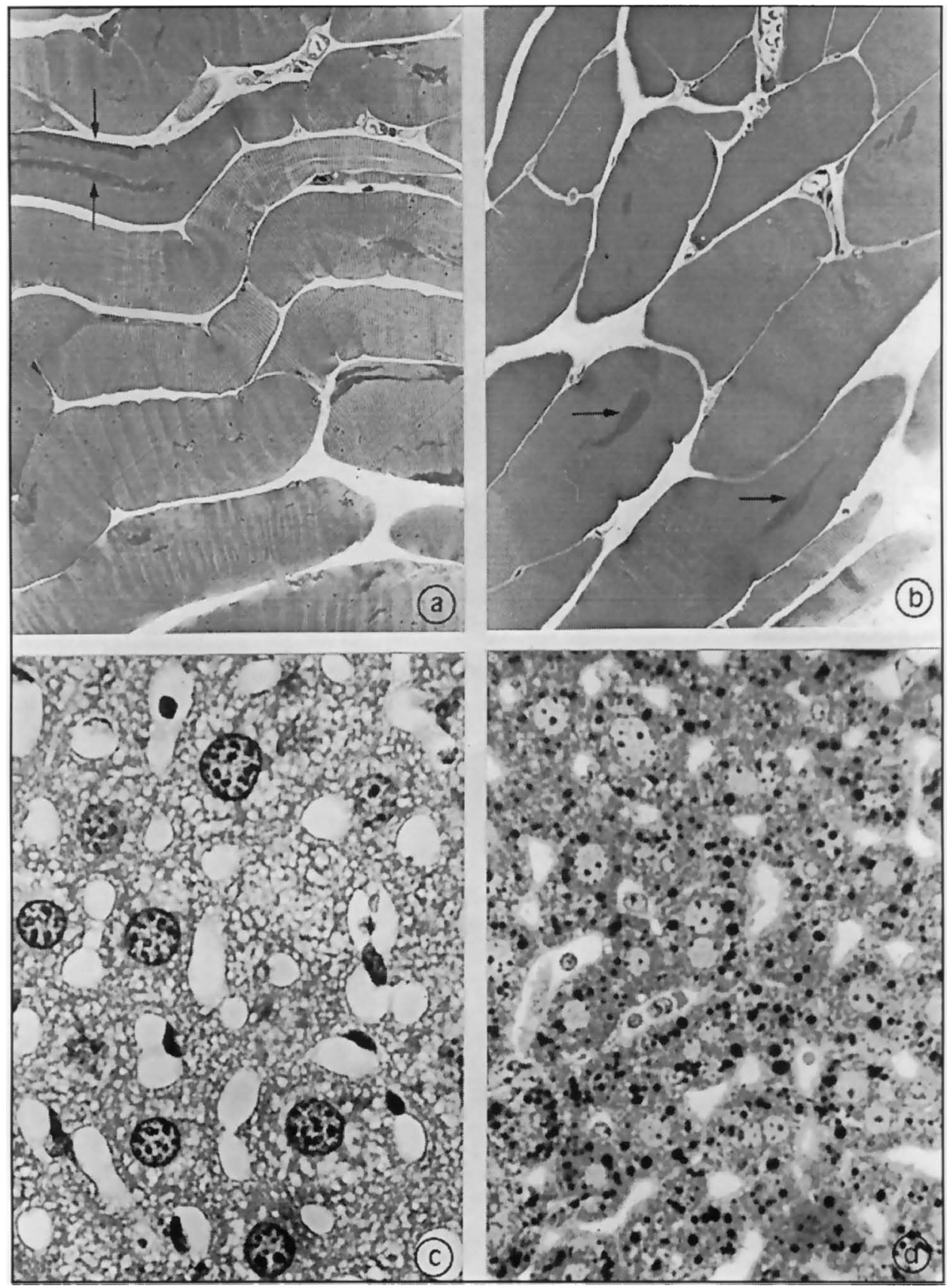

Fig 2. Fotomicrografias. (a) e (b) Cortes semifinos de músculo gastrocnêmio de camundongos controle $e$ alcoólico respectivamente. Observam-se no interior das fibras musculares estruturas alongadas ou elipticas, localizadas abaixo do sarcolema ou no centro das fibras (flechas), correspondente a agregados tubulares. Azure II (400x); (c) Fígado de camundongo alcoólico mostrando hepatócitos com fina e difusa vacuolização citoplasmática. H.E. (400x); (d) Corte semifino de figado do mesmo animal da figura anterior mostrando deposição lipídica do tipo microvesicular no citoplasma dos hepatócitos. Azul de toluidina (400x). 


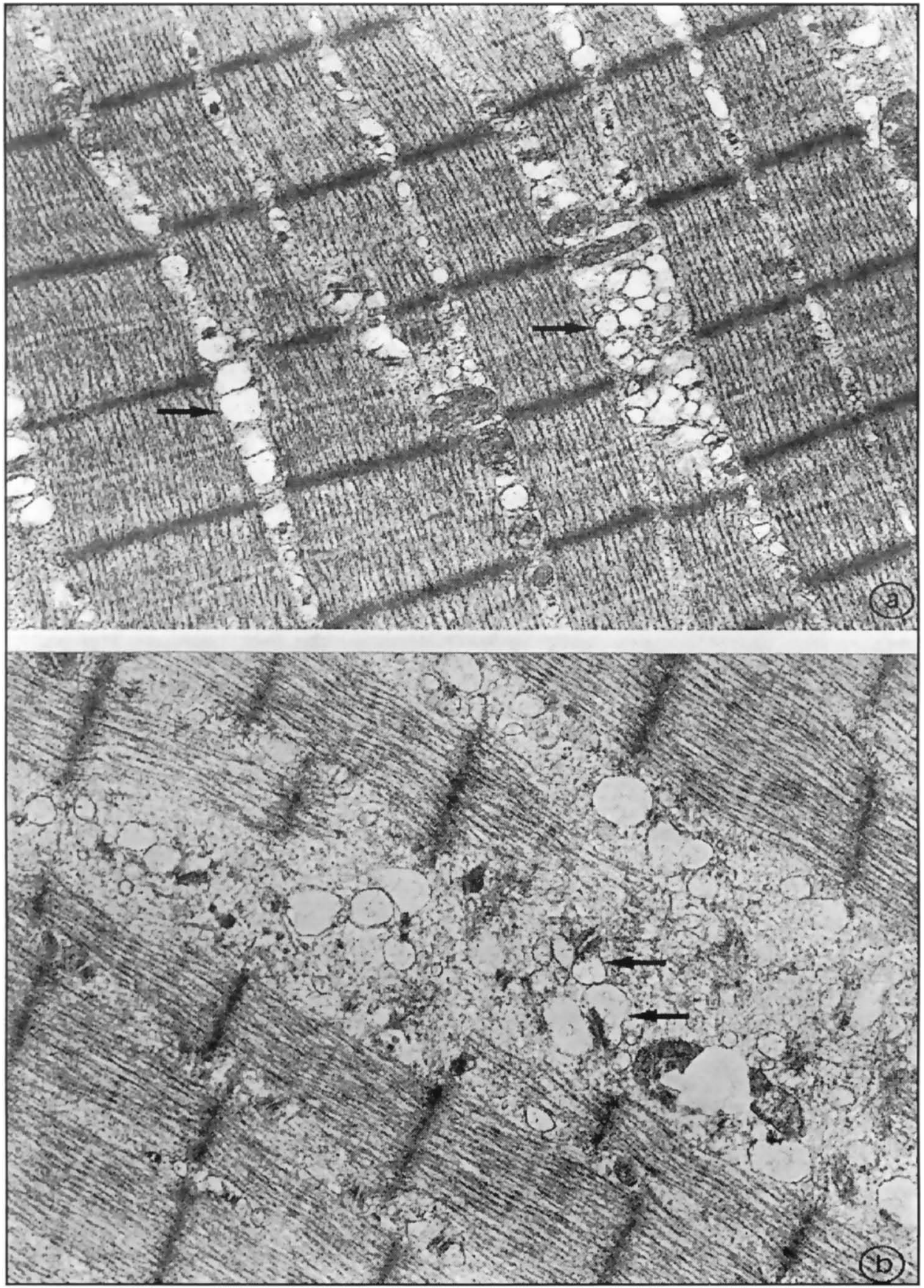

Fig 3. EM. (a) Parte de uma fibra muscular de camundongo alcoólico em estado de contração normal, caracterizada pelo desaparecimetno das bandas I. Observa-se franca dilatação do retículo sarcoplasmático constituindo, por vezes, grandes vesículas (flechas) 30000x; (b)Acentuado grau de dilatação vesicular do reticulo sarcoplasmático. As cisternas terminais (flechas) acham-se igualmente acentuadamente dilatadas, alterando a relação normal das triades com as microfibrilas 30000x. 


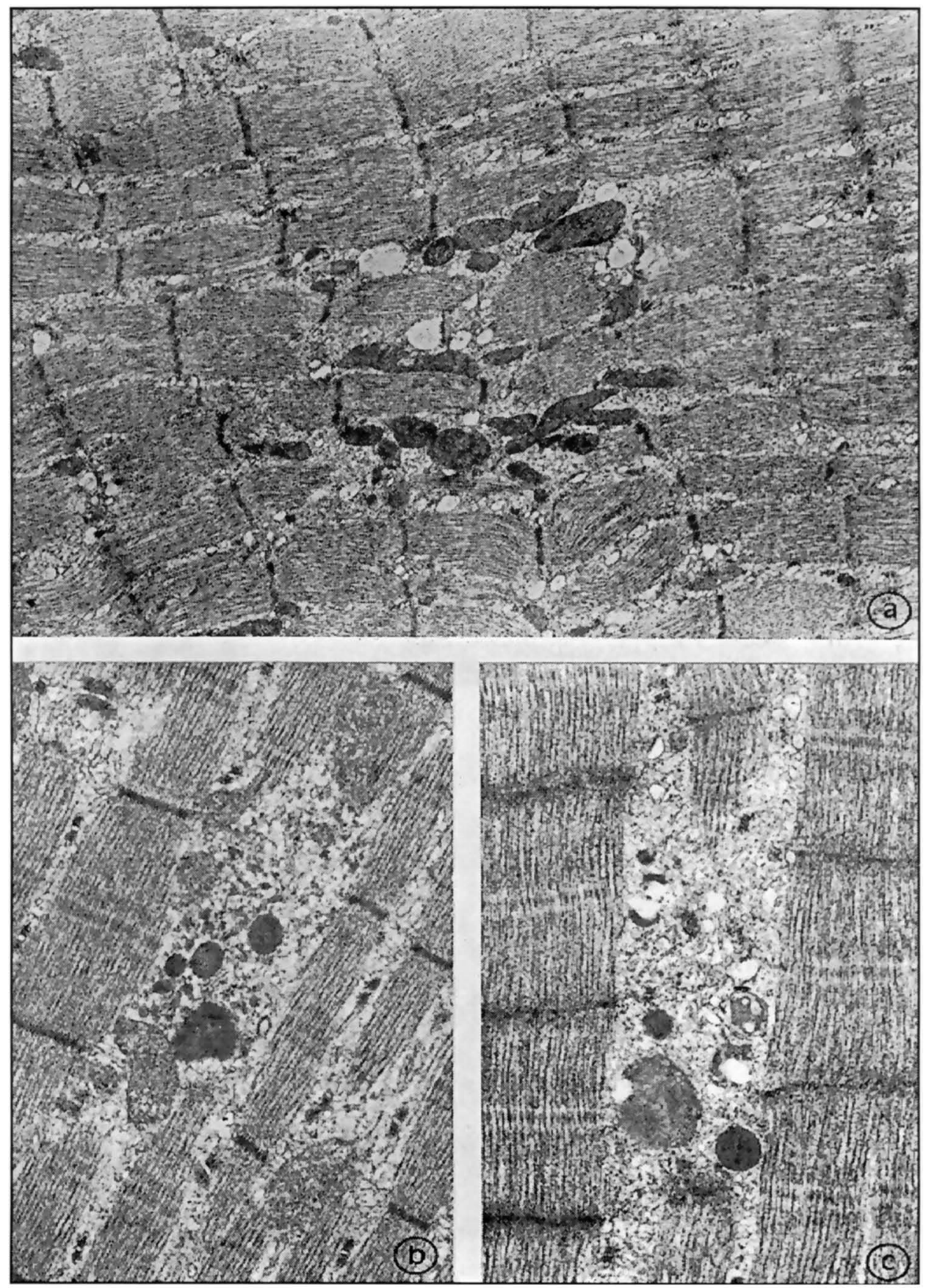

Fig 4. EM (a) Músculo de camundongo alcoólico. Área de ruptura e dissolução de miofibrilas ocupada por mitocôndrias de tamanho e forma variados. Nota-se ainda dilatação do reticulo sarcoplasmático. 18000x; (b) $e$ (c). Músculo de camundongo alcoólico. Em maior aumento aspectos da perda de elementos miocontráteis onde são proeminentes corpos densos lisossomais. Grânulos de glicogênio e remanescentes do reticulo sarcoplasmático são observados. 30000x. 

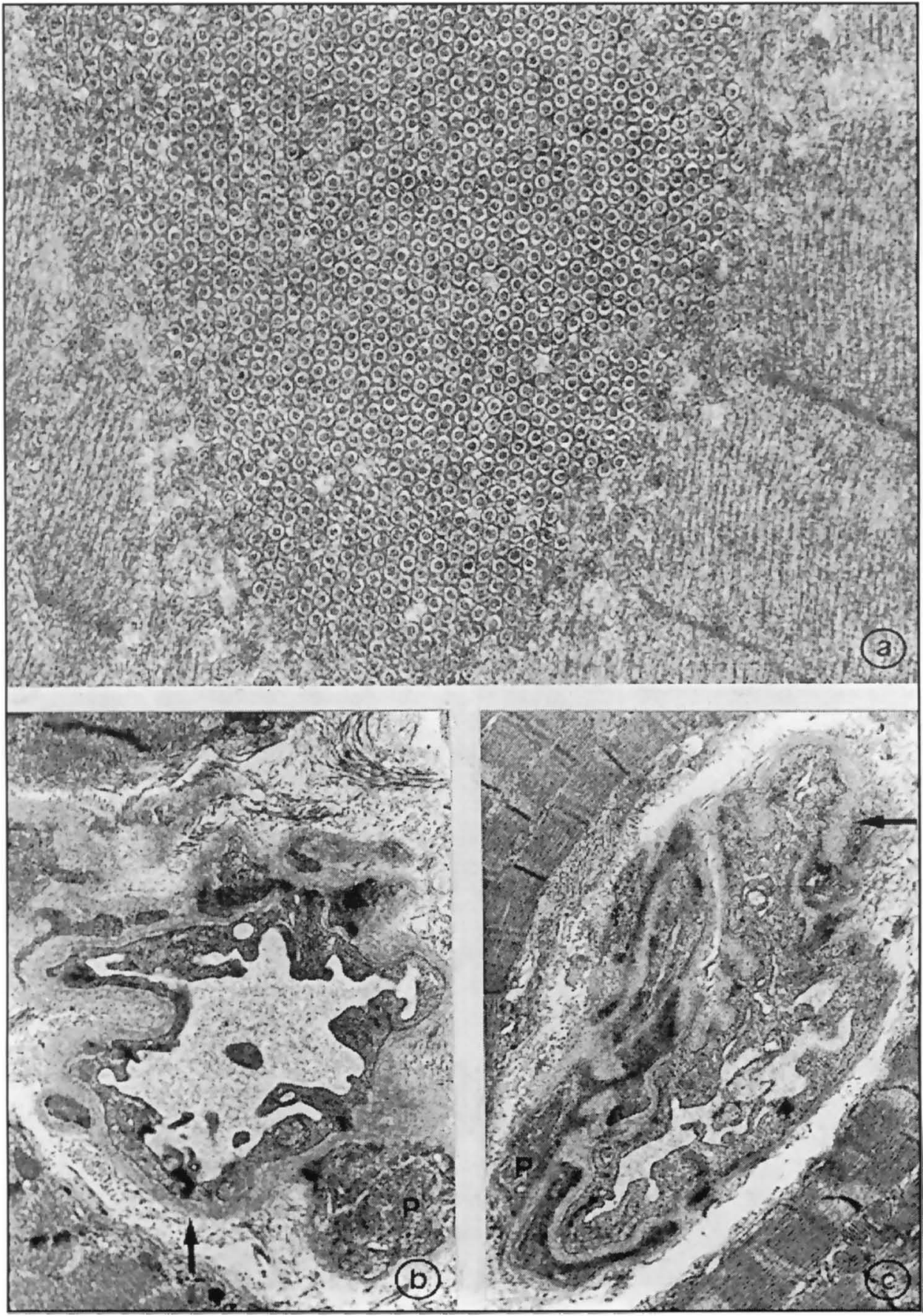

Fig 5. EM. (a) Agregado tubular ocupando parte de fibra muscular de camundongo alcoólico. Cada túbulo apresenta um túbulo interno coaxial 45000x; (b,c) Aspectos de capilares intramusculares de camundongos alcoólicos, ilustrando graus variados de espessamento da lâmina basal (flechas). O espessamento é por vezes intenso conferindo uma acentuada irregularidade à parede capilar. $P=$ Pericito; (b) e (c) 18000x. 
consumiram uma média de $3,8 \mathrm{~g}$ de dieta por dia, correspondente a $14 \mathrm{Kcal}$ de energia metabolizável. Bosshardt e col. ${ }^{2}$, verificaram que a quantidade de proteina ingerida foi o fator mais importante na promoção do crescimento. Knapka e col. ${ }^{17}$ indicaram para o crescimento adequado de várias espécies de camundongo, inclusive o C57BL, uma dieta com concentração protéica bruta de $18 \%$. Ao analisarmos a Tabela verificamos que houve um consumo médio de dieta sólida de $6,07 \mathrm{~g} / \mathrm{camundongo/}$ dia para o Grupo A (controle) e de 4,70 g/camundongo/dia para o Grupo B (alcoólico), correspondendo respectivamente a $21,5 \%$ de calorias/camundongo/dia e $16,7 \%$ de calorias/camundongo/dia. Considerando que normalmente quantidades adequadas de vitaminas e sais minerais fazem parte da composição de toda ração balanceada, podemos dizer que os animais de ambos os grupos ingeriram quantidades adequadas de calorias e nutrientes. $O$ desenvolvimento dos animais, avaliado pela evolução ponderal, foi semelhante (Fig 1). Os camundongos do Grupo B (alcoólico) consumiram $14,4 \%$ do total de calorias sob a forma de etanol. $O$ adoçante não calórico foi adicionado à solução alcoólica a fim de conferir a esta um sabor mais agradável e aumentar a ingestão.

\section{Exame morfológico}

Microscopia óptica. As seç̨ð̃es histológicas do músculo gastrocnêmio dos camundongos do Grupo $\mathrm{B}$ (alcoólico) não mostraram alterações quando comparadas às dos animais do Grupo A (controle). O exame dos cortes semifinos corados pelo Azure Il ou pelo azul de toluidina mostrou no interior das fibras musculares estruturas alongadas ou elípticas, coradas em azul intenso, correspondentes a agregados tubulares. Estudando as alterações morfológicas no músculo de voluntários submetidos ao alcoolismo crônico, Song e Rubin ${ }^{37}$ e Rubin e col. ${ }^{34}$, detectaram importantes alterações ultraestruturais não observadas ao microscópio óptico. Perkof $f^{30}$ chama a atenção para a dificuldade no diagnóstico das chamadas formas subclinicas da miopatia alcoólica crônica quando a elevação das enzimas séricas e uma diminuição do ácido lático em resposta ao exercício isquêmico são praticamente as únicas anormalidades encontradas. Nessas formas, segundo o autor, discretas alterações podem ser vistas ao exame da biópsia muscular tais como leve proliferação dos núcleos subsarcolemais e ocasional atrofia de fibras musculares. A análise ao microscópio óptico das preparações de figado coradas pela hematoxilina-eosina revelou, nos animais alcoólicos, fina vacuolizą̧ão nas células hepáticas correspondendo nos cortes semifinos corados pelo azul de toluidina a moderada deposição lipidica, de distribuição difusa, do tipo microvesicular. Tal observação indica uma provável ação tóxica do etanol sobre o fígado desses animais. Deve-se acrescentar que em nenhum animal foram verificados grandes glóbulos lipídicos no citoplasma que configurassem uma manifesta esteatose hepática.

Microscopia eletrônica. Um achado praticamente constante foi a dilatação do reticulo sarcoplasmático, por vezes intensa, de aspecto vesicular. Tal alteração foi igualmente observada por vários autores na miopatia alcoólica aguda e crônica 13,16,21,34,35,37,39. A dissolução ou lise de miofibrilas por nós mostrada foi raramente relatada no alcoolismo crônico humano ${ }^{13,16,35}$ e experimental ${ }^{1}$. Constitui a nosso ver uma grave alteração se levarmos em consideração que tal perda de elementos miocontráteis foi observada em diminutos espécimens de uma ampla massa muscular.

As mitocôndrias de uma maneira geral estavam bem preservadas, ao contrário das intensas alteraçð̃es relatadas na miopatia alcoólica aguda ${ }^{23,24}$. Nas áreas em que a arquitetura miofibrilar estava mantida, não foram notadas alterações dessas organelas. Nas áreas de ruptura ou de lise da estrutura miofibrilar foram por vezes observados acúmulos de mitocôndrias com forma irregular e tamanho variado, perdendo sua relação habitual com as miofibrilas. Alteraçð̄es das mitocôndrias, na maioria das vezes discretas, foram descritas por alguns autores na miopatia alcoólica crônica humana, tais como: inclusões densas na matriz, irregularidade de forma, tamanho aumentado, cristólise e vacuolização $0^{8,12,13,16,35,37,39}$.

Um excesso de lipídios na miopatia alcoólica crônica foi caracterizado ultraestruturalmente por alguns autores pelo acúmulo de gotículas lipídicas entre as miofibrilas ${ }^{21,34}$. Tal fato não foi constatado em nosso material. 
A presença constante de agregados tubulares no músculo dos animais alcoólicos, idênticos aos encontrados no dos animais controles, merece algumas considerações. Essas estruturas constituem um achado relevante na paralisia periódica, mas são descritas em outras condiçð̄es tais como porfiria, intoxicação por drogas, miotonia distrófica, outras miotonias e, eventualmente, em biópsias de alguns individuos normais ${ }^{6,36}$.

Engel e col. ${ }^{10}$, fazendo uma correlação ultraestrutural e histoquímica em biópsias humanas, relataram a presença de agregados tubulares apenas nas fibras musculares do tipo 2 podendo ocorrer em individuos com leve ou sem qualquer doença neuromuscular. Fato interessante é que, num total de mais de 1500 pacientes biopsiados, todos os 24 que apresentavam agregados tubulares eram homens, embora igual número de mulheres e homens tenham sido biopsiados. Concluíram os autores não haver explicação satisfatória para a formação dos agregados tubulares, para a sua limitação às fibras do tipo 2 e sua preferência pelo sexo masculino. Referem ainda que a intoxicação pelo etanol, entre outras drogas, pode ser uma causa de seu aparecimento Coube a Chui e col. ${ }^{4}$ relatarem detalhadamente pela primeira vez no alcoolismo a presença de extensos agregados subsarcolemais em biópsia do quadriceps de um paciente alcoólico crônico com intoxicação aguda. Sete dias após, numa segunda biópsia, os autores não conseguiram demonstrar qualquer anormalidade. Concluíram assim que sua presença poderia representar uma reação reversível quando fosse removido o presumivel efeito miotóxico do álcool, providos uma adequada nutrição e reidratação. Posteriormente Del Villar Negro e col. ${ }^{7}$ e Trounce e col.$^{38}$ constataram a presença de agregados tubulares em dois de $20 \mathrm{em}$ dois de 10 pacientes alcoólicos crônicos, respectivamente.

Recentes estudos experimentais demonstraram no músculo normal a presença de agregados tubulares. Kunel e col. ${ }^{18}$ observaram agregados tubulares no músculo da panturrilha de camundongos normais da linhagem $M R L+/+$, limitados apenas aos machos da referida linhagem, porém não encontrados em outras linhagens, incluindo MRL +/-, MRL $1 \mathrm{pr} / 1 \mathrm{pr}, \mathrm{BXSB} / \mathrm{MpJ}, \mathrm{BALB} / \mathrm{c}, \mathrm{SJL} / \mathrm{J}$, AJ e C3H HEJ. Admitiram que constituíssem uma ocorrência específica da linhagem MRL $+/+$. Chamaram a atenção para o fato de que a ocorrência de agregados tubulares é limitada amplamente ao sexo masculino em diversas desordens neuromusculares adquiridas e hereditárias. Yoshitoshi e col." trabalhando com camundongos machos normais ICRJJCL observaram que essas estruturas começaram a aparecer no músculo esquelético aos três a quatro meses de idade e foram verificadas em todos os animais acima dos seis a sete meses. Por outro lado, só foram encontradas em dois de 50 camundongos fêmeas, aos 14 e 18 meses de idade. Os resultados desses autores revelaram que os agregados tubulares estavam relacionados ao hormônio testosterona uma vez que a castração dos animais impedia o seu aparecimento.

Salientamos que em nosso experimento os agregados tubulares foram observados no camundongo macho C57BL10, inclusive nos controles, não tendo sido encontrada até o presente momento qualquer referência de sua presença nesta linhagem. É hoje correntemente admitido que estas estruturas resultam de proliferação do retículo sarcoplasmático ${ }^{10.18}$, embora seu significado permaneça não esclarecido ${ }^{26}$.

Em nossa análise ultraestrutural as junções neuromusculares e os nervos intramusculares mostraram padrão condizente à normalidade. Tal observação é importante quando se pretende demonstrar a ação direta doálcool na gênese das alterações musculares na miopatia alcoólica crônica, tendo-se em vista o questionável papel da polineuropatia etilico-carencial. A revisão da literatura nos mostra que os estudos eletromiográficos na miopatia alcoólica têm fornecido resultados variáveis. O eletromiograma pode estar normal, apresentar um padrão miopático ou a combinação de alterações miopáticas e neuropáticas ${ }^{9,13,28}$. Rossouw e col. ${ }^{33} \mathrm{e}$ Langohr e col. ${ }^{19}$ encontraram ao exame eletromiográfico e eletroneurográfico padrão mais frequentemente neuropático. Os estudos histoquímicos revelaram atrofia de fibras do tipo 2, presença de fibras angulares e formação de agrupamentos de fibras do mesmo tipo histoquímico ("fibre type grouping") compativeis com atrofia neurogênica crônica. Em nosso meio Ferraz e col. " estudando pacientes alcoólicos crônicos mostraram 
pela técnica da ATPase atrofia do tipo 2a e alteração da imagem em mosaico à custa de agrupamentos de fibras do mesmo tipo histoquímico, achados estes condizentes com um padrão neuropático. Os autores comentam que muitos casos de miopatia alcoólica crônica apresentam sinais de polineuropatia periférica dificultando sobremaneira a caracterização da miopatia crônica secundária ao alcoolismo. Por outro lado devemos enfatizar que, já na década de 60, Ekbom e col. ${ }^{9}$, realizando investigações eletromiográficas em 16 pacientes alcoólicos, verificaram padrão miopático em 14 pacientes e normal em dois. Estudando 10 pacientes alcoólicos crônicos, Trounce e col. ${ }^{38}$ não encontraram evidência eletrofisiológica de desnervação nos músculos proximais da maioria dos pacientes com atrofia, concluindo não ter sido confirmada pelo seus estudos a sugestão de que a atrofia muscular proximal no alcoolismo tenha usualmente uma base no processo de desnervação. Freitas e col..$^{13}$ estudaram o músculo esquelético de 10 pacientes alcoólicos crônicos, tendo a eletromiografia mostrado padrão miopático em oito pacientes, neuropático em um e normal em um. Nossos estudos ultraestruturais são compativeis com as observações dos autores que demonstraram um padrão essencialmente miopático na miopatia alcoólica crônica, falando em favor de uma ação tóxica direta do etanol sobre o músculo esquelético, independente de qualquer processo neuropático periférico.

Uma observação ultraestrutural de grande relevância foi a presença em nosso material de importantes alterações na microcirculação. Enquanto nos animais controles os capilares intramusculares estavam bem preservados, apresentando paredes delgadas, consistindo de estreito revestimento endotelial apoiado em delicada lâmina basal, graus variáveis de tumefação das células endoteliais e de espessamento da lâmina basal foram verificados nos capilares dos músculos dos animais alcoólicos. São escassas na literatura as informações sobre alteraçðes na microcirculação na miopatia alcoólica. No trabalho de Klinkerfuss e col. ${ }^{16}$, vamos encontrar uma eletronmicrografia onde os autores mostram um capilar com visível espessamento da lâmina basal, mencionado por eles na descrição da figura de um caso crônico de alcoolismo humano; não obstante, não fazem qualquer referência a esta observação no texto do trabalho. Hanid e col..$^{14}$, estudando 15 pacientes portadores de miopatia alcoólica, referem o achado em sete pacientes de um manifesto espessamento da lâmina basal dos capilares musculares. Os autores não fazem qualquer comentário sobre este achado. Dessa forma, não podemos deixar de enfatizar que, no contexto das anormalidades ultraestruturais por nós descritas, constituem as alterações da microcirculação um dos aspectos mais fascinantes do nosso estudo experimental que, sem dúvida, merece posteriores investigações específicas. Uma indagação a ser feita é até que ponto tais alterações, deixando de constituir mera concomitância no elenco das anormalidades aqui descritas, possam desempenhar através de mecanismo isquêmico um papel importante na patogênese das alterações do músculo esquelético no alcoolismo crônico.

Nossos achados experimentais permitem-nos concluir que a ingestão prolongada de etanol por camundongos C57BL 10 bem nutridos é capaz de produzir nestes animais um elenco de alterações ultraestruturais que dão considerável sustentação à teoria de que esse agente desempenha um papel tóxico direto sobre o músculo esquelético. $O$ quadro de alterações por nós descrito guarda grande semelhança com o relatado na literatura em relação à miopatia alcoólica crônica humana

Agradecimento - Aos técnicos do Setor de Microscopia Eletrônica Suely Menezes da Cunha, Rita de Cássia da Costa Cunha, Rosely da Costa Cunha e Ricardo Pascual Barreto pela colaboração nos trabalhos de ultramicrotomia e de fotografia.

\section{REFERÊNCIAS}

1. Baruah J.K, Washington M, Kinder D. Ethanol induced skeletal muscle degeneration: role of calcium. Exp Pathol 1988;33:207-212.

2. Bosshardt DK, Paul WJ, O' Doherty K, Barnes R.H. Caloric restriction and protein metabolism in the growing mouse. J Nutr 1948;36:773-782.

3. Canolty NL, Koong LJ. Utilization of energy for maintenance and for fat lean gains by mice selected for rapid postweaning growth rate. J Nutr 1976;106:1202-1208.

4. Chui LA, Neustein H, Munsat TL. Tubular aggregates in subclinical alcoholic myopathy. Neurology 1975;25:405-412. 
5. Coiro JRR, Brunner A Jr. Comportamento do polylite 8001 com aditivos plastificantes. An Acad Bras Ciênc 1973;45:679-680.

6. Cullen MJ, Johnson MA, Mastaglia FL. Pathological reactions of skeletal muscle.In: Mastaglia FL, Walton J. (eds). Skeletal muscle pathology Ed 2. Edinburgh: Churchill Livingstone, 1992;123-184.

7. Del Villar Negrio A, Merino Angulo J, Rivera Pomar JM, Aguirre Errasti C. Tubular aggregates in skeletal muscle of chronic alcoholic patients. Acta Neuropathol (Berl) 1982;56:250-254.

8. Del Villar Negro A, Merino Angulo J, Rivera Pomar JM. Skeletal muscle changes in chronic alcoholic patients: a conventional, histochemical, ultrastructural and morphometric study. Acta Neurol Scand 1984;70:185-196.

9. Ekbom K, Hed R, Kirstein L, Astrom K-E. : Muscular affections in chronic alcoholism. Arch Neurol 1964;10:449-458.

10. Engel WK, Bishop DW, Cunnigham GG. Tubular aggregates in type II muscle fibers:ultrastructural and histochemical correlation. J Ultrastr Res, 1970;31:507-525.

11. Ferraz ML, Gabbai AA, Oliveira ASB, Ferrari APJ, Miszputen SJ, Ferreira Neto A, Castelo Filho A, Schimdt B. Estudo histoquímico do músculo esquelético no alcoolismo crônico. Atq Neuropsiquiatr 1989;47:139-149.

12. Fisher ER, Puntereri AJ, Jung Y, Corredor DG, Danowski TS. Alcoholism and other concomitants of mitochondrial inclusion in skeletal muscle. Amer J Med Sci, 1971;261:85-99.

13. Freitas MR, Marques HA, Guedes e Silva JB. Associação de miopatia e miocardiopatia alcoólicas: estudo clinico, eletroneuromiográfico e histopatológico do músculo esquelético em 10 casos de miocardiopatia alcoólica. Arq Neuropsiquiatr 1988:46:339-350.

14. Hand A, Slavin G, Mair W, Sowter C, Ward P, Webb J, Levi J. Fibre type changes in striated muscle of alcoholics. J Clin Pathol, 1981;34:991-995.

15. Humphrey CD, Pittman FE. Azure II: basic fuchsin stain for epoxy-embedded tissue sections. Stain Technol 1974;49:9-14.

16. Klinkerfuss G, Bleisch V, Dioso MM, Perkoff GT. A spectrum of myopathy associated with alcoholism. II-light and electron microscopic observations. Anu Intem Med 1967;67:493-510.

17. Knapka JJ, Smith KP, Judge FJ. Effect of crude fat and crude protein on reproduction and weanling growth in four strains of inbred mice. J Nutr 1977;107:61-69.

18. Kunel RW, Peshonk A, Lane J, Alexander E. The MRL +/+ mouse: a new model of tubular aggregates which are gender and age-related. Acta Neuropathol 1989;78:615-620.

19. Langohr HD, Wiethölter H, Pfeiffer J. Muscle wasting in chronic alcoholics: comparative histochernical and biochemical studies. J Neurol Neurosurg Psychiatry, 1983;46:248-254.

20. Lin JH, Duffy JL, Roginsky MS. Microcirculation in diabetes mellitus. Human Pathol 1975;6:77-96.

21. Martin FC, Slavin G, Levi AJ. Al coholic muscle disease. Brit.Med.Bull, 1982;38:53-56.

22. Martin JB, Craig JW, Eckel RE, Munger J. Hypokalemic myopathy in chronic alcoholism. Neurology, 1971;21:1160-1168.

23. Martinez AJ, Hooshmand H, Faris AA. Acute alcoholic myopathy. Enzyme histochemistry and electron microscopic findings. J Neurol Sci, 1973;20:245-252.

24. Munsat TL, Neustein H, Higgins J, Chui L. Experimental acute alcoholic myopathy. Neurology, 1973;23:407.

25. National Academy of Science. Nutrient requirements of laboratory animals. Ed3. Washington: 1978.

26. Nonaka I, Satoyoshi E. Myotonic disorders. In: Mastaglia FL, Walton J. (eds). Skeletal muscle pathology. Ed2. Edinburgh: Churchill Livingstone, 1992;319-342.

27. Organizacion Panamericana de la Salud. Manual para tecnicos en animales de laboratorio. Buenos Aires, Centro Panamericano de Zoonosis, 1974;75-110.

28. Perkoff GT, Hardy P, Velez-Garcia E. Reversible acute muscular syndrome in chronic alcoholism. N Engl J Med, 1966;274:1277-1285.

29. Perkoff GT, Dioso MM, Bleisch V, Klinkerfuss G. A spectrum of myopathy associated with alcoholism: I. Clinical and laboratory features. Ann.Intern.Med, 1967;67:481-492.

30. Perkoff GT. Alcoholic myopathy. Ann Rev Med, 1971;22:125-132.

31. Porta EA, Gomez-Dumm CLA. A new experimental approach in the study of chronic alcoholism: I. Effects of high alcohol intake in rats fed a commercial laboratory diet. Lab Invest, 1968;18:352-364.

32. Rodgers DA, McClean GE. 0, Mouse strain differences in preference for various concentrations of alcohol. Q J Stud Alcohol, 1962;23:26-33.

33. Rossouw JE, Keeton RG, Hewlett RH. Chronic proximal muscular weakness in alcoholics. S Afr Med J, 1976;50:2095-2098.

34. Rubin E, Katz AM, Lieber CS, Stein EP, Puszkin S. Muscle damage produced by chronic alcohol consumption. Amer J Pathol, 1976;83:499-515.

35. Rubin E. Alcoholic myopathy in heart and skeletal muscle. New Engl J Med, 1979;301:28-33.

36. Sewry CA. Ultrastructural changes in diseased muscle. In: Dubowitz V. Muscle biopsy: a practical approach. Ed2. London: Baillière Tindall, 1985:129-183.

37. Song SK, Rubin E. Ethanol produces muscle damage in human volunteers. Science, 1972;175:327-328.

38. Trounce $I, B y m e E$, Dennett $X$. Biochemical and morphological studies of skeletal muscle in experimental chronic alcoholic myopathy. Acta Med Scand, 1990;82:386-391.

39. Urbano-Marquez A, Estruch R, Navarro-Lopez F, Grau JM, Mont L, Rubin E. The effects of alcoholism on skeletal and cardiac muscle. N Engl J Med, 1989;320:409-414.

40. Yoshitoshi M, Ishihara T, Tsugane T, Shinohara $Y$. The effect of sex hormones on tubular aggregates in normal mouse skeletal muscles (Abstr). Rinsho-Shinkeigaku 1991;31:974-980. 